\title{
A Formação do Capital Social na América Central: violência política, repressão, dor e perda'
}

\begin{tabular}{c}
\hline John A. Booth \\
Departamento de Ciência Política \\
University of North Texas \\
Patricia Bayer Richard \\
University College, Ohio University \\
\hline \hline
\end{tabular}

\begin{abstract}
Resumo
A repressão do Estado procura dissuadir os cidadãos de se oporem ao regime e seus programas e fazer com que a sociedade civil e o capital social sirvam aos seus propósitos. Essa repressão pode ir de formas leves de coerção e intimidação ao extremo de infligir dor física aos cidadãos. Os insurgentes também podem reprimir e infligir dor aos cidadãos e assim moldar seus comportamentos e atitudes. Nas décadas de 1980 e 1990, os Estados da América Central e seus oponentes empregaram níveis muito variados de repressão e violência política. No interior dessas nações, os indivíduos perceberam de modo diferenciado a violência e sofreram graus variados de dor e perda. Utilizando dados de surveys dos anos 90 para seis países centro-americanos a fm de examinar os efeitos sobre o capital social da repressão, da violência política percebida e da dor e perda resultantes, concluímos que a repressão sistêmica e a percepção da violência política afetam significativamente a sociedade civil (envolvimento em grupo) e variedades do capital social (participação política, normas democráticas e antidemocráticas, alienação das eleições e disposição para utilizar táticas de confrontação política). Os efeitos da dor e da perda são menos claros. Embora a repressão busque refrear a participação e moldar normas de submissão, seus efeitos na América Central são complexos e, às vezes, inconsistentes com esses objetivos porque ela promove um nível de organização comunal cada vez maior e certas formas confrontadoras de capital social.
\end{abstract}

Palavras-chave: democratização, violência política, ativismo societal, América Central

Abstract

State repression seeks to dissuade citizens from opposing the regime and its programs, and to bend civil society and social capital to regime purposes. Such repression may range from lesser forms of coercion and intimidation to the extreme infliction of physical pain upon citizens. Insurgents, too, may repress and inflict pain upon citizens and thus shape their behavior and attitudes. Central American states and their opponents in the 1980s and early 1990s employed widely varying levels of repression and political violence. Individuals within these nations differentially perceived violence and experienced varying levels of pain and loss stemming from it. Using 1990s survey data from six Central American nations to examine the effects of repression, perceived political violence, and resultant pain and loss upon social capital, we find that repression at the systemic level and the perception of political violence significantly affect civil society (group involvement) and varieties of social capital (political participation, democratic and antidemocratic norms, alienation from elections, and willingness to employ confrontational political tactics). The effects of pain and loss are less clear. While repression seeks to constrain participation and mold compliant norms, its effects in Central America are complex and sometimes inconsistent with such goals because it promotes increased communal level organization and certain confrontational forms of social capital.

Key-words: democratization, political violence, civil society activism, Central America

\footnotetext{
${ }^{1}$ Agradecemos a Chris Gelpi por seus valiosos comentários sobre uma versão anterior deste artigo.
} 
Se "jogar boliche sozinho" é ruim para o capital social, os esquadrões da morte são uma dádiva? Em seu artigo "Bowling Alone", Robert Putnam (1995) sustenta que o declínio da participação em associações voluntárias põe a democracia norte-americana em risco, ao reduzir a formação de tipos importantes de capital social. Mas em sociedades que emergem do autoritarismo ou de forte tumulto político, a repressão e a violência políticas parecem ser muito mais importantes do que a vitalidade das ligas de boliche para moldar associações, atitudes e comportamentos políticos dos cidadãos. Neste artigo, investigamos os efeitos da repressão política, da violência percebida e da dor e perda sobre a participação dos cidadãos em grupos (ativismo na sociedade civil) e sobre o capital social (confiança interpessoal, participação e atitudes políticas) na América Central.

\section{Teoria}

Os regimes, as pessoas que os sustentam e, às vezes, seus oponentes, utilizam a repressão política para influenciar as atitudes e os comportamentos políticos. Por meio da repressão, eles buscam moldar, freqüentemente pela supressão, as atividades dos atores políticos e refrear as demandas e as expectativas dos cidadãos em relação ao regime e ao Estado. A repressão é altamente instrumental. Nas mãos do regime, ela tende a defender o poder, as prerrogativas e os recursos dos governantes e seus aliados das pressões de outras elites e da massa. Nas mãos dos oponentes ao regime, é empregada freqüentemente para atacar o poder dos governantes. Em suas várias manifestações, a repressão serve como instrumento político ao mesmo tempo pontudo e rombudo, agindo diretamente mediante intimidação, coerção, dano ou morte de vítimas especificamente selecionadas e, indiretamente, ao moldar os valores, crenças e comportamentos dos outros que testemunham ou apenas ficam sabendo dela. Por exemplo: os cidadãos que sofrem diretamente a repressão podem alterar suas opiniões e, em especial, mudar o modo como interagem com os outros, o Estado ou movimentos políticos. Mas mesmo aqueles que apenas percebem ou temem a repressão podem mudar o comportamento e as atitudes para evitar que se tornem alvos também. Esses impactos amplos e indiretos da repressão moldam a natureza e a distribuição do capital social numa sociedade (Booth \& Richard, 1998a, 1998b) e há indícios de que a violência política disseminada provoca efeitos semelhantes (Booth, 2000).

Os estudos existentes sobre repressão política são principalmente descritivos, históricos e centrados no Estado, concentrando-se em suas origens, desenvolvimento, papéis, relações com o autoritarismo e efeitos sobre instituições e forças sociais. ${ }^{2}$ Os estudiosos também examinaram amplamente as ligações complexas entre repressão e conflito político (p. ex. Gurr, 1970; Tilly, 1978; Gurr \& Harff, 1994; Lichbach, 1995). Poe e Tate (1994) documentaram o crescimento rápido do estudo da repressão per se,

\footnotetext{
${ }^{2}$ Mesmo restrita à América Latina, essa literatura é imensa demais para ser citada. Boas bibliografias gerais podem ser encontradas em Lichbach (1995) e Mason e Krane (1989). Bibliografias voltadas para a América Latina encontram-se em Collier (1979, pp.405-443) e Loveman, Davies e Beezley (1997).
} 
especialmente medida como desempenho em direitos humanos dos regimes. ${ }^{3}$ Outra linha de pesquisa explora como os níveis de desenvolvimento econômico, o tipo de regime, a ideologia e os interesses moldam o desempenho governamental em direitos humanos ( $p$. ex. Petras et al., 1986; Pion-Berlin, 1989; Barsh, 1993, pp.87-90; Poe \& Tate, 1994; Davenport, 1995, 1999; King, 1999) e como a repressão afeta o comportamento da oposição (Gurr, 1970, 1986; Duff \& McCamant, 1976; Mason \& Krane, 1989; King, 1998; Lichbach, 1995). Estudos recentes revelam que as democracias novas ou emergentes têm taxas mais altas de repressão do que as estabelecidas há mais tempo (Fein, 1995; Regan, 1999).

Jennings (1999, p.1) introduz um conceito potencialmente útil nessa área de estudo. Em sua investigação de 1999 sobre respostas políticas à dor e perda, definidas como "exposição a eventos envolvendo dano físico, ferimento, doença ou morte, seja vivida pessoal e diretamente ou experimentada de modo mais remoto e vicário", ele sustenta que "as experiências de dor e perda penetram no âmago da vida cotidiana e freqüentemente infundem nela a política"; afirma também que "as respostas a eventos de dor e perda ocupam um lugar proeminente nos domínios da opinião pública e do ativismo em torno de questões". Embora seu foco seja o impacto da AIDS, Jennings (1999, pp.7-9) propõe que a repressão, as agressões e a guerra civil também geram grandes dores e perdas e assim podem afetar de modo significativo a formação do capital social, mudar crenças e contribuir para a mobilização política.

Uma área promissora de pesquisa aborda o modo como a repressão estatal afeta a sociedade civil e o capital social no nível individual, em especial as atitudes políticas e a participação dos cidadãos (Gibson, 1988; Corradi et al., 1992; Booth \& Richard, 1996, 1998a, 1998b). Como a repressão estatal se destina a limitar ou controlar o comportamento dos cidadãos, é razoável se esperar que ela diminua a participação e restrinja as expressões de apoio à democracia. Pesquisa comparativa recente (Booth \& Richard, 1996; 1998a, 1998b) mostra que a repressão medida em nível nacional geralmente diminui o apoio dos centro-americanos às normas democráticas e reduz a participação política. Por outro lado, a repressão pode produzir conseqüências políticas não pretendidas por quem a utiliza. No nível do sistema, a repressão estatal pesada pode estimular, em vez de desencorajar, a mobilização da oposição ao regime. Outros indícios sugerem que o efeito da repressão sobre o envolvimento dos indivíduos na sociedade civil e na formação do capital social pode ser complexa. Embora a participação e o apoio expresso à democracia pareçam mais baixos nos regimes repressivos, a participação em grupos e a disposição dos cidadãos para protestar ou enfrentar o Estado podem aumentar nesses contextos (Booth, 1991; Foley \& Edwards, 1996).

\footnotetext{
${ }^{3}$ Um ramo dessa literatura trata da repressão como um variável independente na formação da política pública (p. ex. Poe, 1990, 1991). Outra trata da repressão do regime como uma variável dependente e busca explicar as variações em violação dos direitos humanos e repressão (p. ex. Stohl \& Lopez, 1984, 1986, 1988; Petras et al., 1986; Gastil, 1989; Corradi et al., 1992; Poe \& Tate, 1994).
} 
Portanto, perguntamos: como os cidadãos reagem à repressão política, a períodos extensos de violência política e de dor e perda, especialmente em democracias novas e emergentes? Como as percepções dos cidadãos dos níveis de violência e suas experiências de dor e perda induzidas pela repressão afetam o capital social? Eles participam mais ou menos, ou de modo diferente, sob condições de repressão? Eles se associam mais ou evitam associar-se para aumentar sua segurança?

A turbulenta região centro-americana oferece um excelente contexto comparativo para procurar respostas a essas perguntas. Utilizamos dados de pesquisas de opinião pública urbana em países da América Central para investigar essas questões, examinando várias hipóteses a respeito do impacto da repressão, da violência política e da dor e perda sobre a sociedade civil e a formação do capital social.

Começamos com a relação entre repressão estatal, violência política percebida e experiência pessoal de dor e perda. Tratamos a repressão estatal como um constrangimento no nível da sociedade sobre os indivíduos. Captamos a violência política em termos de percepção individual e consideramos capazes de produzir violência política tanto a repressão do Estado como as ações da oposição insurgente. A repressão no nível do sistema deveria aumentar tanto as percepções individuais da violência como as experiências de dor e perda, ao mesmo tempo em que a experiência individual de dor e perda deveria contribuir para as percepções de violência. Portanto:

H1a. Repressão maior no nível do sistema aumentará as percepções individuais de violência política.

H1b. Repressão maior no nível do sistema aumentará as experiências individuais de dor e perda.

H1c. Níveis individuais mais altos de dor e perda aumentarão os níveis de violência percebida.

Acreditamos que repressão, percepções de violência e dor e perda influenciarão a formação do capital social, uma massa de atitudes e comportamentos que moldam as interações dos cidadãos entre eles e com o Estado. ${ }^{4}$ As pesquisas anteriores, citadas acima, sugerem que a confiança interpessoal, o apoio ao sistema, a participação política e as normas democráticas são mais baixas em regimes repressivos e esperamos efeitos

\footnotetext{
${ }^{4}$ Um número crescente de estudiosos (Edwards \& Foley, 2001; Foley \& Edwards, 2000; Schudson, 1998; Rosenblum, 1998; Berkowitz, 1999; Booth \& Richard, 1998a, 1998b) sustenta que abordagem da ciência política da concepção de capital social principalmente em termos de confiança interpessoal (ver Putnam, 1995, 2000) é profundamente falha. Nós concordamos e concluímos que o constructo de capital social vago de Putnam pode ser útil se redefinido como "capital político", uma forma de capital social que consiste de atitudes, valores e comportamentos que invade o governo de alguma forma. Enquanto alguns desses valores, comportamentos e atitudes podem aumentar a civilidade promovendo a democracia e a participação dos cidadãos nas instituições, outras podem reduzir a civilidade, aumentar o conflito político ou enfraquecer as normas democráticas (Armony, 1999; Booth \& Richard, 1998c; Diamond, 1999; Richard \& Booth, 2000). Assim, incluímos nesta análise, além da confiança interpessoal, as variáveis de capital social do tipo capital social, algumas que aumentam a civilidade, outras que a reduzem.
} 
similares da violência percebida ou da experiência de dor e perda. Isso sugere as seguintes hipóteses:

H2: Repressão maior no nível do sistema, maior violência política percebida e mais experiências de dor e perda diminuirão os níveis de confiança interpessoal dos cidadãos e de apoio difuso ao sistema político.

H3: Repressão maior no nível do sistema, maior violência política percebida e mais experiências de dor e perda diminuirão os níveis de participação política em canais estabelecidos (votar, contatar autoridades e fazer campanha).

H4: Repressão maior no nível do sistema, maior violência política percebida e mais experiências de dor e perda diminuirão os níveis de apoio às liberdades democráticas.

Por outro lado, repressão, violência e dor e perda podem também induzir à mobilização, com os cidadãos se organizando para a proteção e benefício mútuo. Os cidadãos podem tentar se insular ou defender seus interesses em um ambiente político hostil ou ameaçador por meio da ação coletiva. Mediante a participação em um grupo, os indivíduos podem ser socializados em atitudes e crenças políticas que reforçam o grupo e fortalecem sua capacidade de empreender uma ação coletiva mutuamente benéfica. Diferentes tipos de organização, dependendo dos recursos e da posição de classe de seus membros, cultivarão assim diferentes tipos de capital social. Por exemplo: enquanto os grupos comunitários podem promover o contato com autoridades para obter recursos, os grupos de trabalhadores podem estimular a desobediência civil como uma arma política valiosa para os desprivilegiados. ${ }^{5}$

H5: Repressão maior no nível do sistema, maior violência política percebida e mais experiências de dor e perda aumentarão os níveis de ativismo da sociedade civil (envolvimento em grupos).

Por fim, os cidadãos que vivem sob repressão, que percebem violência ou que sofrem dor e perda podem se tornar alienados do sistema político ou antagonistas em relação ao governo. Desse modo, podem evidenciar formas de capital social alienadas ou de confronto, que podemos chamar de capital político negativo.

H6: Repressão maior no nível do sistema, maior violência política percebida e mais experiências de dor e perda aumentarão os níveis de apoio à desobediência civil, de apoio à supressão das liberdades democráticas, de justificação de golpes de estado, de apoio à derrubada do governo e de alheamento das eleições.

\footnotetext{
${ }^{5}$ Ver Booth e Richard (1998) e Richard e Booth (2000)
} 


\section{América Central}

A América Central do começo da década de 1990 constitui um campo promissor para investigar o impacto da repressão, da violência política e da dor e perda. Os seis principais países da região compartilham há muito tempo muitos traços culturais e sociais - experiências históricas, língua, cultura social, religião, tamanho pequeno e economia permitindo assim uma comparação de sistemas muito semelhantes. Porém, eles variam enormemente em suas situações políticas nacionais - tipos de regime, graus de democracia efetiva e níveis de repressão e violência (Booth \& Walker, 1999). Embora os seis países tivessem governos formalmente democráticos no começo dos anos 90 , com a realização de eleições, vários deles ainda estavam desenvolvendo suas instituições e lutando para resolver violentos conflitos políticos internos. A Costa Rica era uma democracia estável havia décadas. Honduras estava avançando gradualmente para uma democracia civil. Na Nicarágua, acabara recentemente uma década de revolução e contra-revolução sandinista. El Salvador e Guatemala ainda estavam mergulhados em guerras civis intensas, com as negociações de paz salvadorenhas fazendo progressos muito mais rápidos do que as guatemaltecas. O Panamá fora invadido pelos Estados Unidos em 1989, para derrubar a ditadura de Noriega e instalar um governo civil.

\section{Dados}

Os dados desta análise provêm de surveys realizados entre 1991 e 1995 dos residentes urbanos de seis países da América Central: Costa Rica, El Salvador, Guatemala, Honduras, Nicarágua e Panamá. ${ }^{6}$ Os seis surveys partilharam um grande núcleo de itens idênticos, sobre percepções de violência política, ativismo em grupo, participação política e atitudes e valores políticos. Muitos desses itens foram amplamente validados e testados em campo em vários cenários culturais (Booth \& Seligson, 1984; Muller et al., 1987; Seligson \& Gomez, 1989; Seligson \& Booth, 1993). Quatro dos surveys incluíam também itens sobre dor e perda oriundas de tumulto político.

\footnotetext{
${ }^{6}$ Metodologia: os surveys foram realizados na metade de 1991 entre a população urbana e em idade de votar de El Salvador, Honduras, Nicarágua e Panamá. Em 1992, survey semelhante foi realizado na Guatemala e em 1995, na Costa Rica. Em cada um deles, uma amostra de grupo estratificada (por nível socioeconômico) foi retirada da capital nacional e de outros centros urbanos importantes. Os entrevistados foram selecionados conforme procedimentos aleatórios e cotas por sexo e idade. Um total de 4.089 entrevistas pessoais foram realizadas em toda a região, com as amostras nacionais variando de 500 a 900 . Para evitar que os números de país grande distorcessem os resultados, as amostras nacionais foram ponderadas igualmente para aproximadamente 700 cada ( $\mathrm{N}=4.198$, ponderado). Generalizamos somente para as maiores áreas urbanas, cerca de metade da população da região.

Agradecemos o apoio para a coleta de dados das seguintes instituições: North-South Center of the University of Miami; Howard Heinz Endowment for Latin American Studies of the University of Pittsburgh Research Grants on Current Latin American Issues; University of North Texas Faculty Development Grants and Faculty Research Programs; Andrew Mellon Foundation; Tinker Foundation; Heinz Foundation; e University of Pittsburgh. O projeto foi criado e boa parte dos dados foram coletados por uma equipe que incluía Mitchell A. Seligson, da Universidade de Pittsburgh, e John A. Booth, da Universidade do Norte do Texas. Para mais detalhes, ver Booth e Richard (1996).
} 
Variáveis independentes. A medida de repressão estatal trata a repressão como um constrangimento sistêmico sobre indivíduos no nível da sociedade. Ela inclui dois componentes igualmente ponderados: um que mede a repressão na época do survey e outro, a história da repressão na década anterior ao survey. A média proporciona um escore de repressão para cada país que nós designamos para cada respondente por nação de residência. ${ }^{7}$

Enquanto a repressão é um fenômeno com base no Estado, a violência política inclui danos a cidadãos e propriedades perpetrados tanto pelas forças do regime quanto por elementos paramilitares e pelos oponentes do regime. Os cidadãos que vivem em países onde há terrorismo estatal e insurgente enfrentam um cenário social cheio de riscos potenciais. Utilizamos um item que pergunta aos cidadãos sobre quanta violência política eles percebem, proporcionando uma medida em nível individual de violência percebida.

Quatro dos seis países sofreram altos níveis de repressão e violência política. El Salvador, Guatemala e Nicarágua passaram por insurreições prolongadas e campanhas contra-insurreição e por repressão de moderada a violenta. O regime de Noriega, no Panamá, sob forte pressão americana, também usou a repressão estatal e depois sofreu a invasão de 1989 que o derrubou. Nesses quatro países, os surveys incluíram uma bateria de três itens que mapeiam a dor e perda individual derivada da violência e repressão: se um membro da família do entrevistado fora morto ou estava desaparecido, se estava refugiado ou tivera de deixar o país.

A tabela 1 apresenta escores por país e região para essas variáveis independentes, bem como um índice de dor e perda, e oferece detalhes sobre a construção das medidas. ${ }^{8}$ Esses itens foram combinados para formar um índice de dor e perda. Correlações de ordem zero entre essas medidas revelam que elas não são multicolineares (tabela 3).

Medidas da sociedade civil. As respostas a questões concernentes à atividade em sete tipos de organizações proporcionam a base para nossos índices de sociedade civil (ver notas da tabela 2). A análise fatorial de variáveis que medem a participação dos cidadãos em grupos e associações detectou dois modos distintos de atividade na sociedade civil. Chamamos o primeiro de envolvimento em grupo formal (que inclui participação em sindicatos, associações cívicas, cooperativas e grupos profissionais). Chamamos o segundo de envolvimento comunal (em grupos comunitários tais como organizações de pais e mestres, grupos de desenvolvimento comunitário e trabalho em projetos na comunidade). As médias de ambas as medidas diferiram significativamente

\footnotetext{
${ }^{7}$ A medida contém um componente histórico (intensidade estimada de repressão do regime durante a década anterior), sob a suposição de que o efeito da repressão sobre os cidadãos diminui gradualmente, mesmo depois do fim dela. O contexto imediato da repressão também importa, de forma que a repressão é estimada em cada país na data do survey. Ver Booth e Richard (1996) para mais detalhes sobre a construção e validação dessa medida.

${ }^{8}$ Deve-se observar que os valores registrados para os componentes de dor e perda não significam, por exemplo, que $47.7 \%$ dos nicaragüenses foram para o exílio, mas sim que alguém da família extensa do entrevistado se exilou.
} 
entre as nações (tabela 2).

Variáveis de capital social. Concebemos capital social de forma ampla, indo muito além da confiança interpessoal, ${ }^{9}$ para incorporar dois conjuntos de medidas que indicam potencialidades essenciais entre os cidadãos -apoiar a democracia e participar nela (capital social que reforça a civilidade) e perturbar, enfrentar e desafiar as instituições políticas (capital social que reduz a civilidade ou promove o conflito). Do lado positivo, temos três medidas de participação dos cidadãos na política através de canais normativos, isto é, aceitos - votar, contatar autoridades e fazer campanha (ver notas da tabela 2 para detalhes). Outro item incorpora medidas múltiplas de dois conceitos-chave gerais, apoio a direitos de participação gerais e à tolerância, que estão combinados numa medida de normas democráticas (ver tabela 2 para detalhes).

Em nossa análise, utilizamos também vários itens que captam aspectos de capital social de diminuição de civilidade ou de aumento de conflito. Além de uma crença expressa em que um golpe de estado poderia se justificar (justificativa de golpe), outros derivam de uma bateria de questões enraizadas na literatura de cultura cívica e poliarquia: um índice que mede a aprovação da supressão de liberdades democráticas dos respondentes ( $p$. ex. aprovação da censura à imprensa ou da proibição de manifestações); um índice que mede a aprovação da desobediência civil dos respondentes (p. ex., ocupação de prédios ou bloqueio de ruas); um item que revela a aprovação da rebelião armada contra um governo eleito; ${ }^{10} \mathrm{e}$ um item final sobre alienação das eleições. ${ }^{11}$

Medidas demográficas. Uma vez que se sabe que certos traços demográficos influenciam o comportamento e as atitudes dos cidadãos e desse modo afetam as relações que estamos examinando, empregamos como variáveis de controle medidas de padrão de vida, educação e sexo dos respondentes.

\footnotetext{
${ }^{9}$ Como observamos antes, Foley e Edwards (2000) sustentam que a confiança interpessoal diz pouco sobre a formação do capital social e seus efeitos sobre as características do sistema. Incluímos a confiança interpessoal aqui com propósito comparativo.

${ }^{10}$ Ver Seligson e Booth (1993) para uma discussão detalhada da literatura de tolerância e poliarquia da qual derivam esses itens.

${ }^{11}$ Isso se baseia nas explicações dos respondentes sobre porque os cidadãos não votaram nas últimas eleições. Atribui o escore 1 aos entrevistados que afirmaram que os outros não acreditam em eleições, estavam desiludidos com elas ou não queriam votar;às outras respostas atribuiu-se zero.
} 


\section{Análise}

Começamos nossa análise com um exame das relações preditas entre repressão em nível de sistema, violência percebida e dor e perda em H1a-H1c. A tabela 3 apresenta correlação de ordem zero entre essas variáveis. A análise confirma $\mathrm{H1a}$, revelando uma correlação forte e positiva entre repressão estatal e violência percebida em todos os seis países ( $r=.509$ ), bem como na sub-amostra dos mais turbulentos $(r=.432)$. encontramos também sustentação para $H 1 c$ : nas quatro nações mais turbulentas, a violência percebida e dor e perda estão correlacionadas positivamente, embora não de maneira tão forte.

Por outro lado, $H 1 b$ prediz que a repressão estatal estará associada com mais experiências individuais de dor e perda, mas nossa análise revela, ao contrário, uma relação negativa significativa (tabela $3 \mathrm{~A}$ ). Suspeitamos que a interação de estilos de repressão estatal (por exemplo, o fato de a repressão ter um alvo mais limitado em um país do que em outro) com a população urbana do survey produz o resultado inesperado. O Panamá, por exemplo, tem um índice de dor e perda mais alto do que a Guatemala, refletindo provavelmente a alta incidência de violência nas zonas urbanas durante o regime de Noriega e a invasão de 1989. As populações indígenas fortemente vitimadas da Guatemala, residentes rurais em sua maioria, estão sub-representadas em nossa amostra urbana. Mediante o exame de dados de 1993 e 1995 obtidos por surveys de amostras nacionais de dois estágios de 2.400 guatemaltecos que incluíam moradores urbanos e rurais e muitos indígenas, ${ }^{12}$ descobrimos uma considerável variação regional na Guatemala em níveis de violência percebida, sugerindo que contextos subnacionais podem influenciar essa relação quando examinados por meio de amostras nacionais.

Em suma, há fortes indícios a favor da hipótese de vínculos positivos entre repressão estatal e violência percebida e entre violência percebida e dor e perda. $A$ correlação negativa repressão-dor/perda parece ser um produto artificial da composição da amostra.

Voltamo-nos agora para a formação de capital social, começando com o apoio difuso ao sistema político e a confiança interpessoal. $\mathrm{H} 2$ prediz que altos níveis de repressão e violência percebida irão diminuir tanto o apoio como a confiança. A tabela 4 apresenta a análise de regressão múltipla do impacto sobre nosso índice de apoio difuso da repressão estatal, violência percebida e dor e perda, bem como várias variáveis de controle para traços demográficos, exposição à mídia e níveis de informação. ${ }^{13}$ Ao contrário da predição de $H 2$, a repressão estatal tem um efeito positivo sobre o apoio difuso nas duas amostras de quatro e seis países (modelos 1 e 2). Porém, como H2 previa, a violência política percebida diminui marcantemente o apoio difuso. Com efeito, os centro-americanos vivendo em regimes repressivos que percebem menos violência

\footnotetext{
${ }_{12}^{12}$ Agradecemos a Mitchell Seligson por esses dados.

${ }^{13}$ Ver notas da tabela 4 para detalhes sobre a construção de índices para as variáveis exposição à mídia e nível de informação.
} 
tendem a fazer profissões de patriotismo e orgulho institucional levemente mais fortes. Se pensarmos, esse padrão tem uma lógica: o contexto repressivo insta os cidadãos a professar orgulho patriótico, algo que parece que as pessoas que não estão percebendo pessoalmente violência excessiva fariam com maior probabilidade.

Em contraste, o desempenho da confiança interpessoal está, em larga medida, dentro do previsto por $H 3$, sendo diminuída pela repressão estatal (somente no modelo de quatro países) e por níveis mais altos de violência percebida (tanto na tabela 4 como nos modelos 3 e 4). Porém, explica-se muito pouco da variância em confiança interpessoal ( $2.0 \%$ no modelo $3,3.5 \%$ no modelo 4$)$, mesmo quando feita a regressão sobre vários fatores demográficos. O índice de dor e perda não tem novamente correlação independente significativa com apoio difuso ou confiança expressa em outros em qualquer dos quatro modelos apresentados na tabela 4.

Para testar $\mathrm{H} 3$ e $H 4$, fizemos a regressão de medidas de participação política total e normas democráticas totais sobre nossas medidas de repressão, violência percebida e dor e perda. A tabela 5 revela que repressão e violência percebida diminuem a participação na política na amostra de seis países (modelo 1); somente repressão faz o mesmo para a sub-amostra de quatro países (modelo 2). A medida de dor e perda não tem impacto significativo sobre a participação política em ambos os modelos. Desse modo, os resultados confirmam H5 para repressão, o confirmam parcialmente para violência percebida e não o confirmam para dor e perda. Em termos de normas democráticas, os dois modelos revelam que a repressão tem fortes efeitos negativos, enquanto que violência percebida e dor e perda não têm nenhum efeito. Portanto, a repressão estatal é o fator que de modo consistente e agudo reduz duas formas essenciais de capital social entre os centro-americanos, participar na política normativa e sustentar normas democráticas. $O$ fato de que isso aconteça, enquanto a violência percebida e dor e perda têm pouco ou nenhum efeito, sugere que nossos variados fenômenos de repressão e violência talvez exerçam influências diferenciadas sobre os diversos tipos de capital social.

A tabela 6 apresenta os resultados de análises de regressão de duas formas de envolvimento na sociedade civil, tal como discutidas acima: envolvimento em grupo formal, que compreende a participação em associações cívicas, grupos profissionais, cooperativas e sindicatos, e envolvimento comunal, que indica atividade em organizações com foco local, tais como melhoria da comunidade, igreja e escola. Embora $\mathrm{H} 5$ preveja que repressão, violência percebida e dor e perda estarão associadas a níveis mais altos de atividade na sociedade civil, a hipótese não se confirma com respeito a dor e perda. Por outro lado, é verdade que os centro-americanos participam mais em grupos comunitários em regimes mais repressivos e quando percebem altos níveis de violência. Em termos de participação em grupos formais, não vemos nenhum efeito da repressão, mas um efeito significativamente negativo da violência percebida.

Esses resultados indicam que nossas variáveis independentes têm efeitos 
mobilizadores diferenciados para diferentes tipos de grupos, com padrões distintos ligando repressão e violência a cada forma de capital social. As relações dos diferentes tipos de grupos com o regime sugerem explicações possíveis para os efeitos variáveis da repressão e da violência percebida sobre o capital social dos cidadãos.

Grupos comunitários. Em vez de ser suprimido, tal como se supunha, descobrimos que o envolvimento comunal dos cidadãos é maior sob condições de repressão e violência percebida. Entendemos que essas relações derivam do foco local dos grupos comunais. Eles oferecem oportunidades para melhoria - pouca, mas real que representam pouca ameaça para os regimes e, portanto, constituem espaços em que os cidadãos podem participar, mesmo em ambientes políticos violentos e repressivos. Os grupos comunitários oferecem refúgio seguro para que os ativistas persigam seus objetivos sem que sejam vistos como desafios ao regime.

Grupos formais. Os grupos formais têm maior possibilidade de aparecer na tela dos radares do regime, embora diferentes tipos de grupos possam variar nas demandas ou no apoio que transmitem ao regime. Nossa medida de grupo formal abrange diversos tipos de organizações, que representam cidadãos de diferentes classes e com interesses bem distintos. Os membros típicos dos sindicatos e das cooperativas são trabalhadores e a classe média baixa, cujos objetivos podem incluir a redistribuição da riqueza e dos serviços para os menos privilegiados. Na América Central, os sindicatos estão especialmente inclinados a contestar a política salarial do governo e assim, podem ser vítimas da repressão estatal. Por outro lado, os membros de associações cívicas e profissionais tendem a vir das classes média e alta. Suspeitamos que os membros desses grupos, estando muito menos propensos a ser contra o regime, podem esquivar-se da repressão e da violência e até prosperar sob regimes que os empregam.

Investigamos essas conjeturas explorando o efeito de nossas três variáveis independentes sobre o ativismo em cada tipo de grupo formal, ${ }^{14}$ e desse modo identificamos efeitos divergentes da repressão e violência. Como esperávamos, a repressão estatal maior está associada com menor participação em sindicatos e cooperativas e com maior ativismo em grupos profissionais. Em contraste, os que percebem violência política mais alta parecem não sentir estímulo para se envolver em associações profissionais e cívicas. ${ }^{15}$

Voltamo-nos agora para os tipos de capital social que podem ser rotulados de "capital político negativo" - normas antidemocráticas, bem como atitudes que endossam ou justificam o comportamento político violento ou expressam alheamento político (Armony, 1999; Booth \& Richard, 1998c; Diamond, 1999, p.227; Richard \& Booth, 2000). O capital político negativo é aquele que reduz a civilidade, aumenta o conflito político no interior da nação e enfraquece os valores democráticos. A hipótese 6 prediz que níveis

\footnotetext{
${ }^{14}$ Não incluído aqui por motivos de espaço.

15 Ver Booth e Richard (1998c) e Richard e Booth (2000) para uma discussão de como a repressão afeta de modo diferenciado a sociedade civil e o capital social por tipo de grupo.
} 
mais altos de repressão estatal, violência percebida e dor e perda estarão associados ao capital político negativo. Uma vez mais, nossa medida de dor e perda não teve efeitos significativos (resultados não incluídos para economizar espaço). Os resultados para repressão e violência percebida exibidos na tabela 7 (que exclui a medida de dor e perda) são complexos e revelam novamente influências diferenciadas sobre capital social da repressão estatal e da violência percebida. A repressão maior está correlacionada com menor aprovação da desobediência civil e justificação de golpe de estado, mas com apoio maior para suprimir liberdades democráticas e mais alienação das eleições.

O quadro é um pouco mais claro no que se refere à violência percebida: a hipótese é corroborada com respeito à justificação de golpes, derrubada de governo e alienação das eleições, mas não para supressão de liberdades civis. Os cidadãos dos Estados mais repressivos da América Central e aqueles que percebiam altos níveis de violência estavam logicamente alienados das eleições e haviam feito pouco para produzir a paz. Além disso, os que percebem violência tendem também a aprovar mais a derrubada de governo e a justificar golpes. Esses resultados confirmam parcialmente que cidadãos reprimidos ou temerosos aderem a orientações de confronto contra o Estado.

Por fim, voltamo-nos para alguns padrões mais amplos que emergem da revisão das tabelas 4 a 7 . Está claro que a repressão estatal e a violência percebida deixam sua marca distintiva sobre o capital social. Em cada modelo de regressão registrado, uma delas ou ambas têm um efeito estatisticamente significativo sobre a variável dependente. Mas quão fortes são os efeitos? Eles variam consideravelmente. Como fica demonstrado pelo $\mathrm{R}^{2}$, nossos modelos mais bem sucedidos respondem por entre $9 \%$ e $19 \%$ de variância explicada em três variáveis dependentes - participação política total, envolvimento em grupo formal e normas democráticas gerais. Em contraste, a variância explicada é muito limitada ( $3,5 \%$ ou menos) para várias variáveis: confiança interpessoal, justificação de golpes, aprovação da derrubada do governo e alienação das eleições. A variância explicada é apenas levemente mais robusta (na faixa dos 4 a 6\%) para o envolvimento comunal e apoio difuso, apoio à desobediência civil e apoio à supressão de liberdades civis.

Supomos que a diferença em variância explicada entre o primeiro grupo e os dois grupos posteriores de variáveis surge de várias fontes. Em primeiro lugar, as variáveis mais bem explicadas consistem de fenômenos que aumentam a civilidade, são socialmente aceitáveis e ocorrem no interior de canais - por exemplo, apoio às normas democráticas, votar, contatar autoridades, participação em associações cívicas e profissionais, ou seja, capital social positivo. Ao contrário, muitas das variáveis menos explicadas consistem de capital político negativo - redutor de civilidade, apoio a conflito ou respostas alienadas possivelmente sujeitas a um viés de desejabilidade social. Alguns entrevistados talvez tenham relutado em admitir esses comportamentos de redução da civilidade, introduzindo assim erros nos dados. Em segundo lugar, suspeitamos que o capital social e os fenômenos de sociedade civil no grupo mais bem explicado estão mais 
bem medidos do que os menos explicados. As variáveis mais bem explicadas consistem principalmente de índices construídos a partir de itens múltiplos e foram repetidamente validadas em diversos cenários políticos. Os fenômenos no grupo menos explicado são medidos por itens simples - justificação de golpe, alienação das eleições e apoio à derrubada do governo - e podem, portanto, ser menos confiáveis. Outra das variáveis mal explicadas é a confiança interpessoal, que medimos da forma usual, mas que é cada vez mais criticada em termos teóricos, conceituais e de medida (Power \& Clark, 1999; Foley \& Edwards, 2000). Desse modo, medidas de capital político negativo e confiança interpessoal podem ser mais desenvolvidas e refinadas em estudos futuros. Em terceiro lugar, as variáveis menos explicadas tendem a ter menores desvios-padrão e assim, menos variância para explicar do que as variáveis de capital social mais bem explicadas.

\section{Resumo e conclusões}

Nossos resultados podem ser resumidos da seguinte forma: em primeiro lugar, a repressão estatal e a violência percebida reduzem a confiança interpessoal, revelando um forte efeito contextual sobre o capital social. Em contraste, o apoio difuso ao sistema político é mais baixo entre os que mais percebem a violência, tal como se supunha, mas mais alto entre cidadãos de regimes mais agressivos. Esse resultado anômalo pode derivar da falta de disposição dos cidadãos para expressar aos entrevistadores suas reservas sobre governos altamente repressivos.

Em segundo lugar, a repressão estatal e a violência percebida reduzem os níveis de participação política e normas democráticas. Como se supunha, ambas aumentam certos tipos de ativismo na sociedade civil (em grupos comunais e em associações profissionais). Mas contrariando as hipóteses, a repressão estatal reduz a participação em sindicatos e cooperativas e a violência percebida diminui o envolvimento em associações profissionais e cívicas. Desse modo, os efeitos da repressão e da violência percebida variam conforme o tipo específico de organização.

Em terceiro lugar, a repressão estatal e a violência percebida aumentam a alienação dos cidadãos em relação às eleições, sua disposição expressa de suprimir liberdades civis e sua disposição para justificar um golpe de estado e apoiar a derrubada do governo.

Em quarto lugar, a repressão estatal e a violência percebida influenciam as variáveis do capital social de modo diferenciado. A repressão, por exemplo, é o principal fator na redução da participação e das normas democráticas, enquanto que a violência percebida é fator principal na redução da confiança interpessoal, da participação em grupos formais e na disposição de derrubar o governo. Em alguns casos, a repressão estatal e a violência percebida influenciam em direções opostas as variáveis do capital social.

Por fim, as experiências de dor e perda têm muito pouco efeito independente 
sobre a formação do capital social.

Em suma, a repressão e a violência percebida na América Central, tal como se esperava, enfraquecem o capital político positivo, ou formas de capital social que aumentam civilidade tais como normas democráticas, participação política e confiança interpessoal. A repressão e a violência percebida também contribuem para o capital político negativo, aumentando a alienação das eleições, a disposição para suprimir liberdades democráticas, a justificação de golpes e o apoio à derrubada do governo. Desse modo, regimes com níveis mais altos de repressão e percepção de violência disseminada entre os cidadãos militam contra o desenvolvimento da civilidade, do capital político positivo e promovem o capital político negativo de redução da civilidade.

Nossa medida de dor e perda, baseada na experiência dos respondentes de morte, fuga ou exílio de membros da família revelou-se infrutífera para a predição de níveis de capital social quando a repressão estatal e a violência percebida também foram incluídas. Isso apresenta uma questão interessante: seria o próprio conceito problemático, ou se trata de um caso de mensuração inadequada?

Tentamos responder a essa questão fazendo uma análise de regressão país por país, excluindo assim a variável repressão estatal. ${ }^{16}$ Desse modo, descobrimos alguma influência de dor e perda sobre o capital social. Especificamente, dor e perda explicavam níveis significativos de variância na maioria das variáveis dependentes no caso do Panamá: tal como previa nossa hipótese, os panamenhos que registravam dor e perda eram mais ativos tanto em grupos formais como em comunais e estavam mais dispostos a apoiar a desobediência civil e derrubar o governo. Além disso, os salvadorenhos na mesma situação tinham menos normas democráticas. Contudo, ao contrário de nossa hipótese, os nicaragüenses tinham níveis mais altos de participação política.

Tendo em vista esse aprofundamento da questão da dor e perda, sugerimos as seguintes explicações para sua falta de impacto sobre o capital social quando considerado em termos regionais. Em primeiro lugar, na América Central do começo dos anos 90, as experiências individuais de dor e perda talvez tenham tido menos influência do que as perspectivas sociotrópicas. Isto é, os indivíduos talvez tenham respondido com base no que parecia estar acontecendo com outros, ou outros como eles, independente de suas experiências próprias. Isso abafaria o efeito específico de uma experiência de dor e perda pessoal. Em segundo lugar, a experiência de dor e perda proporciona uma disposição comportamental retrospectiva. Essa retrospecção sobre uma perda pessoal ou familiar talvez seja menos frutífera do que explorar o ambiente político existente para encontrar disposições prospectivas relacionadas com a repressão atual e a violência política percebida. Em essência, a consideração da repressão e da violência sugeriria a muitos cidadãos estratégias para ajustar suas ações atuais e opiniões expressas de forma a evitar o risco político.

\footnotetext{
${ }^{16}$ Análise regressiva não mostrada aqui por motivos de espaço.
} 
Uma terceira explicação para o mau desempenho de dor e perda é que o desenho do survey pode ter enfraquecido a potência do conceito. Como dissemos, estudamos apenas amostras urbanas. A interação de padrões de migração decorrentes de conflito civil e o timing dos surveys nacionais com respeito às guerras civis pode ter efetivamente eliminado muitos vítimas de dor e perda de algumas amostras nacionais. Ao não incluir mensurações de dor e perda nos surveys dos dois países menos turbulentos da região (Costa Rica e Honduras), perdeu-se a variância potencial. Por outro lado, os efeitos de dor e perda que discernimos em nossa análise nacional indicam que elas podem mobilizar cidadãos e gerar capital político negativo. Portanto, cremos que os efeitos da dor e perda exigem uma investigação mais aprofundada.

Nossa pesquisa sobre a América Central nos permitiu considerar os efeitos das patologias políticas da repressão, violência percebida e experiência de dor e perda sobre o capital social. Levando em conta o debate teórico sobre se a atividade na sociedade civil e o resultante capital social aumentam necessariamente a civilidade ou o capital político positivo, ou se eles podem, às vezes, reduzir a civilidade e promover o capital político negativo, partimos para examinar a formação de capital social na América Central. A teoria e pesquisas anteriores sugeriam que o contexto político tinha muita importância na formação do capital social. Portanto, nós sustentamos que a repressão estatal, a violência política percebida e a dor e perda provavelmente diminuiriam o capital político positivo ou intensificador de civilidade, mas também aumentariam a formação de capital político negativo ou redutor de civilidade. Apesar de algumas limitações e certas anomalias interessantes, confirmamos, em larga medida, as expectativas com respeito à repressão estatal e à violência percebida. Embora inconcludente aqui, justifica-se um aprofundamento da pesquisa sobre os efeitos da dor e perda. 
TABELA 1

Medidas de níveis de repressão, violência percebida e dor/perda para habitantes urbanos centro-americanos, por país.

\begin{tabular}{|c|c|c|c|c|c|c|c|}
\hline & Guatemala & Honduras & El Salvador & Nicarágua & Costa Rica & Panamá & Região \\
\hline $\begin{array}{l}\text { Nível Contextual } \\
\text { Nível de repressão }^{a}\end{array}$ & 5.00 & 2.00 & 4.50 & 3.00 & 1.00 & 1.50 & 2.83 \\
\hline $\begin{array}{l}\text { Nível Individual } \\
\text { Nível de violência percebida }{ }^{\text {b }}\end{array}$ & 3.44 & 1.44 & 3.79 & 3.17 & 1.75 & 2.15 & 2.62 \\
\hline $\begin{array}{l}\text { Membro da família morto ou } \\
\text { desaparecido }(\%)^{d}\end{array}$ & 9.0 & $-^{c}$ & 22.9 & 19.4 & $-{ }^{c}$ & 6.7 & $-{ }^{c}$ \\
\hline Membro da família refugiado $(\%)^{\mathrm{e}}$ & 6.6 & $-^{c}$ & 30.9 & 42.4 & $-{ }^{c}$ & 6.9 & $-c$ \\
\hline Membro da família no exílio(\% $)^{f}$ & 7.7 & $-c^{c}$ & 33.6 & 47.7 & $-{ }^{c}$ & 6.9 & $-^{c}$ \\
\hline Índice de dor e perda & .09 & $-c$ & .26 & .30 & $-{ }^{c}$ & .17 & $-c$ \\
\hline
\end{tabular}

Índice de repressão no nível do sistema; metade do escore baseada no nível à época do survey, metade do escore baseada na repressão durante a década anterior ao survey; escore é média; repressão muito baixa $=1 \ldots$ repressão muito alta $=5$. Ver Booth e Richard (1996) para detalhes sobre a construção de índices.

Item: "Quanta violência política há no país?" nenhuma=1, alguma=2, muita=3.

Não disponível; questão não formulada em países sem guerra civil.

Item: "Algum membro de sua família foi morto ou desapareceu durante a violência política?" Valores = percentagem que respondeu afirmativamente.

Item: "Algum membro de sua família esteve refugiado por causa da violência política?" Valores = percentagem que respondeu afirmativamente.

Item: "Algum membro de sua família teve de deixar o país por causa da violência política?" Valores = percentagem que respondeu afirmativamente.

Índice de dor e perda devido violência política; construído baseado em respostas afirmativas aos itens morte/desaparecimento, refugiado, e exílio acima.(intervalo de $0=$ baixo a $3=$ =alto). 
A Formação do Capital Social na América Central

TABELA 2

Índices da sociedade civil e capital social para habitantes urbanos centro-americanos, por país. ${ }^{a}$

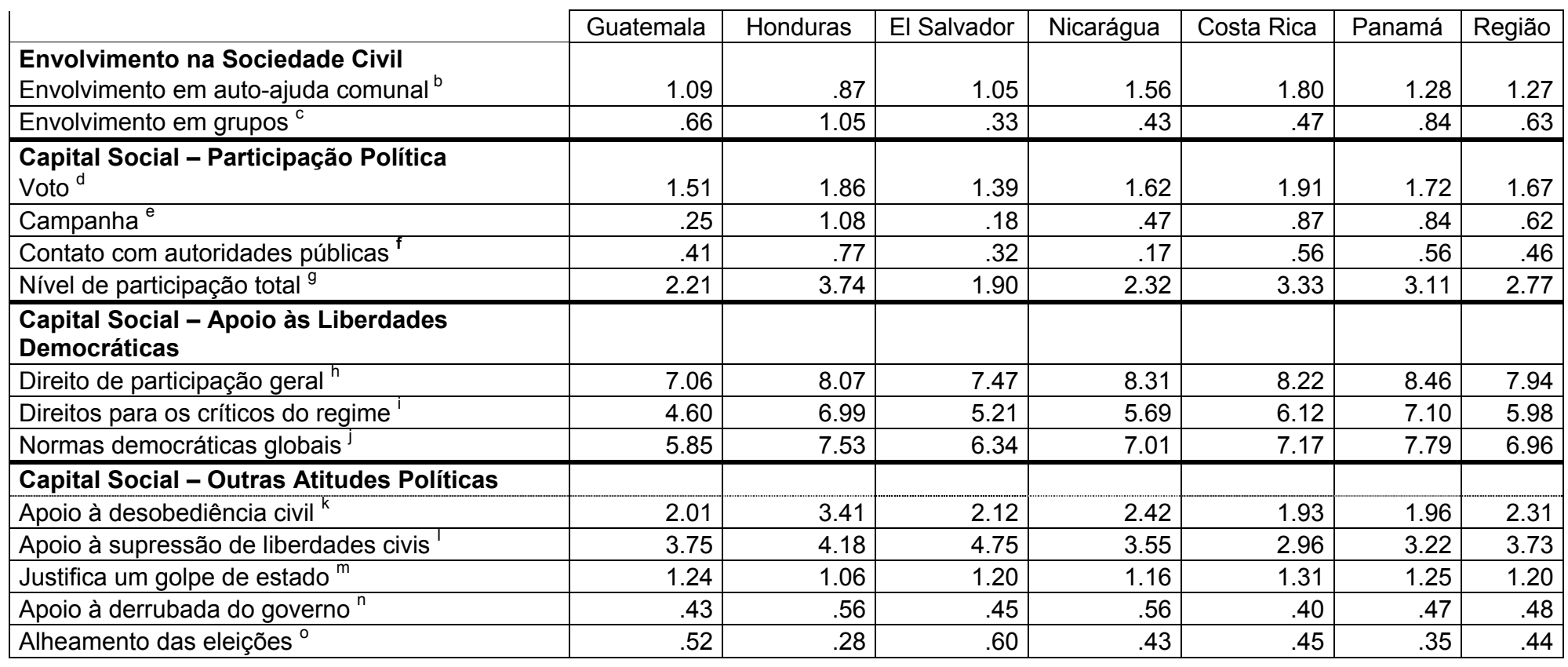

As diferenças de médias entre países em todos os items são significativas no nível .0001 ou maior.

Envolvimento em cinco atividades de auto-ajuda comunitárias; $1=\operatorname{sim}, 0=$ não para cada; escala $=0-5$

Comparece às vezes a sindicato, associação cívica, cooperativa ou associação profissional; sim $=1$, não=0 para cada; escala $=0-4$

Registrou-se para votar e votou na última eleição; $\operatorname{sim}=1$, não=0 para cada; escala 0-2.

Tentou persuadir outros sobre como votar ou trabalhou na última ou penúltima campanha eleitoral; $1=\operatorname{sim}, 0=$ não para cada; escala $=0-3$.

Teve algum contato com presidente, deputado, vereador, ou agência do governo nacional; sim, $0=$ não para cada; escala = 0-4.

Índice de participação política total; soma os escores dos índices de voto, contato, e campanha acima; escala = 0-9.

Índice de apoio aos direitos de participação geral baseado em 3 itens; escala 1 - 10.

Índice de apoio a 3 direitos de participação de críticos do regime (tolerância); escala 1-10.

Indice total de apoio a liberdades democráticas (média aritmética de apoio a direitos de participação geral e aos direitos de participação de críticos; escala = 1 - 10 .

Índice de apoio a desobediência civil e comportamento de protesto (4 itens), escala 0-10.

Índice de apoio à supressão de liberdades civis (apoio a censura etc.), escala 0-10.

Item: "Há alguma justificativa para um golpe de estado?" (1=não, 2=sim).

Item medindo apoio à tentativa violenta de derrubar o governo eleito:1=apóiam fortemente... 10=desaprovam fortemente.

Item: Respondente acha que os não-votantes não acreditam em eleições. (0=não, 1=sim) 
TABELA 3

Relações (correlações de ordem zero) entre repressão estatal, violência política percebida, e dor e perda.

A. Amostra de quatro países (exclui Costa Rica e Honduras).

$\begin{array}{lccc} & \text { Repressão Estatal } & \text { Violência percebida } & (\mathrm{N}) \\ \text { Violência percebida } & .432^{* * *} & - & .054^{* *}\end{array}$

B. Correlação entre repressão estatal e violência percebida, Amostra de seis países:

$\underline{r} \quad \underline{(N)}$

$.509^{* * * *}(4096)$

C. Correlações entre perda e dor e violência percebida, por país

$\begin{array}{lccc} & \underline{r} & \frac{(\mathrm{N})}{(651)} \\ \text { Guatemala } & .017 & (696) \\ \text { El Salvador } & -.051 & (667) \\ \text { Nicarágua } & .019 & (651) \\ \text { Panamá } & .163^{* * *} & (19)\end{array}$

Níveis de significância: ${ }^{*} \leq .05 ;{ }^{* *} \leq .01 ;{ }^{* *} \leq .001 ;{ }^{* * *} \leq .0001$. 


\section{TABELA 4}

Regressão múltipla, índices de apoio difuso individual e confiança interpessoal sobre repressão, violência percebida, dor e perda, contato com mídia, informação política e fatores demográficos (coeficientes beta), América Central urbana.

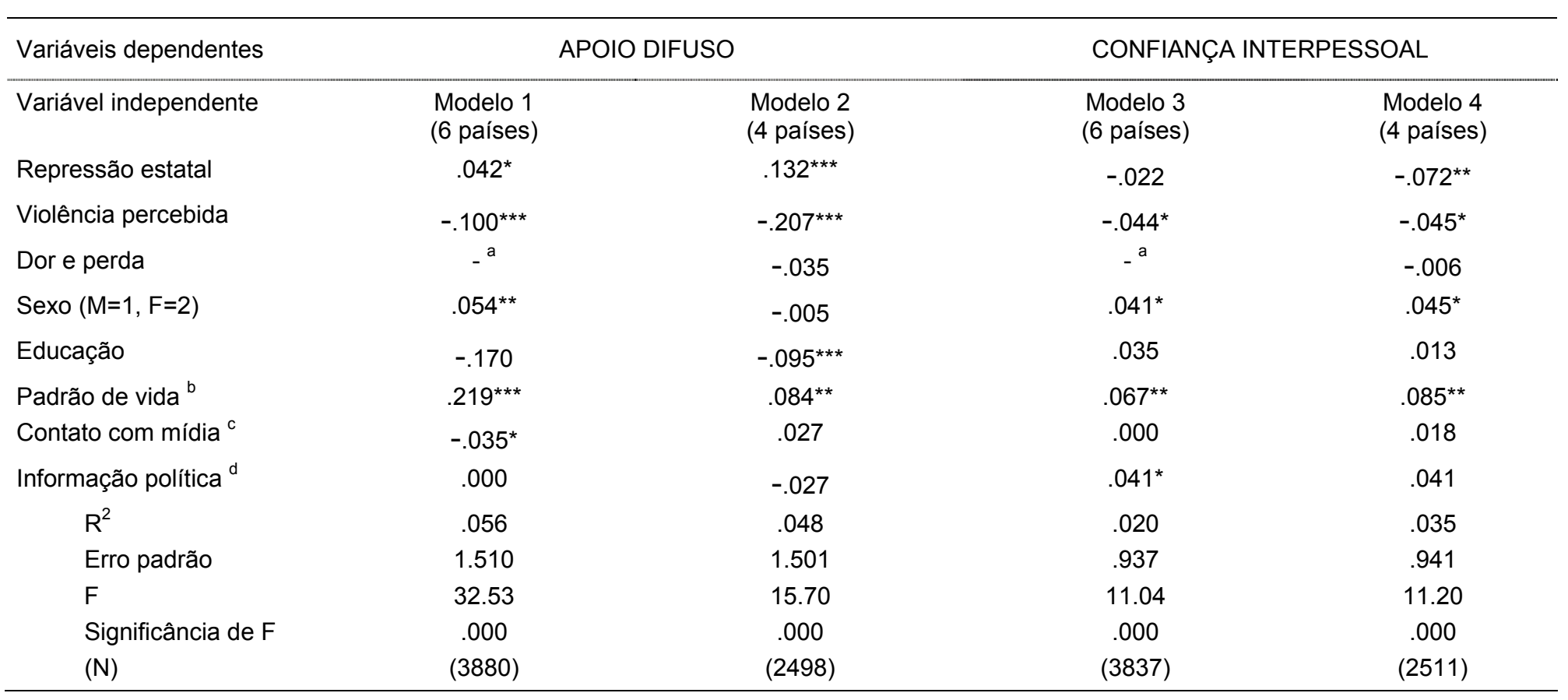

Níveis de significância: * $\leq .05 ;{ }^{* *} \leq .01 ;{ }^{* * *} \leq .001$

Item não disponível na amostra de 6 países.

15.

Padrão de vida é um índice de riqueza familiar baseado na propriedade de televisões em cores, refrigeradores, máquinas de lavar, telefones e automóveis; escala 0 -

Um índice de contato com mídia informativa baseado em escuta declarada de notícias na televisão, rádio, e leitura diária de jornais; escala 0 - 3.

Um índice de informação/conhecimento político baseado nas respostas corretas a questões sobre o nome do Secretário de Estado dos EUA, do presidente da

Rússia, e número de deputados da câmara de deputados; escala 0 - 3.

Item não disponível na amostra de 6-países. 
OPINIÂO PÚBLICA, Campinas, Vol. VII, $n^{\circ} 7,2001, p p .75-99$

TABELA 5

Regressão múltipla, participação individual e normas democráticas sobre repressão, violência percebida, dor e perda, contato com mídia, informação política e fatores demográficos (coeficientes beta), América Central urbana.

\begin{tabular}{|c|c|c|c|c|}
\hline \multirow{2}{*}{$\begin{array}{l}\text { Variáveis dependentes } \\
\text { Variável independente }\end{array}$} & \multicolumn{2}{|c|}{ PARTICIPAÇÃO POLÍTICA } & \multicolumn{2}{|c|}{ NORMAS DEMOCRÁTICAS } \\
\hline & $\begin{array}{l}\text { Modelo } 1 \\
\text { (6 países) }\end{array}$ & $\begin{array}{l}\text { Modelo } 2 \\
\text { (4 países) }\end{array}$ & $\begin{array}{l}\text { Modelo } 3 \\
\text { ( } 6 \text { países) }\end{array}$ & $\begin{array}{l}\text { Modelo } 4 \\
\text { (4 países) }\end{array}$ \\
\hline Repressão estatal & $-.286^{* * *}$ & $-.200^{* * *}$ & $-.271^{* * *}$ & $-.301^{* * *}$ \\
\hline Violência percebida & $-.092^{* \star *}$ & -.009 & .033 & -.008 \\
\hline Dor e perda & $-a^{a}$ & .023 & $-{ }^{a}$ & -.019 \\
\hline $\operatorname{Sexo}(M=1, F=2)$ & $-.108^{* * *}$ & $-.098^{* * *}$ & -.010 & -.034 \\
\hline Educação & $.072^{* * *}$ & $.056^{*}$ & $.071^{* * *}$ & $.095^{* * *}$ \\
\hline Padrão de vida ${ }^{\text {b }}$ & $-.050^{* *}$ & .023 & -.004 & -.041 \\
\hline Contato com mídia ${ }^{\mathrm{C}}$ & $.098^{\star * *}$ & $.081^{* * *}$ & .003 & .025 \\
\hline Informação política ${ }^{\text {d }}$ & $.078^{\star * *}$ & $.110^{* * *}$ & $.245^{\star \star *}$ & $.192^{* * *}$ \\
\hline $\mathrm{R}^{2}$ & .174 & .119 & .158 & .181 \\
\hline Erro padrão & 1.49 & 1.40 & 1.88 & 1.88 \\
\hline $\mathrm{F}$ & 115.05 & 41.95 & 107.03 & 69.84 \\
\hline Significância de F & .000 & .000 & .000 & .000 \\
\hline$(\mathrm{N})$ & (3828) & $(2502)$ & (3845) & $(2532)$ \\
\hline
\end{tabular}

Níveis de significância: * $\leq .05 ;{ }^{* *} \leq .01 ;{ }^{* *} \leq .001$.

Item não disponível na amostra de 6 países.

Ver Tabela 4 para detalhes sobre a construção de índices. 
TABELA 6

Regressão múltipla, envolvimento individual em grupos formais e envolvimento comunal sobre repressão, violência percebida, dor e perda, contato com mídia, informação política e fatores demográficos (coeficientes beta), América Central urbana.

\begin{tabular}{|c|c|c|c|c|}
\hline \multirow{2}{*}{$\begin{array}{l}\text { Variáveis dependentes } \\
\text { Variável independente }\end{array}$} & \multicolumn{2}{|c|}{ ATIVISMO EM GRUPO FORMAL } & \multicolumn{2}{|c|}{ ATIVISMO EM GRUPO COMUNAL } \\
\hline & $\begin{array}{l}\text { Modelo } 1 \\
\text { (6 países) }\end{array}$ & $\begin{array}{l}\text { Modelo } 2 \\
\text { (4 países) }\end{array}$ & $\begin{array}{l}\text { Modelo } 3 \\
\text { (6 países) }\end{array}$ & $\begin{array}{l}\text { Modelo } 4 \\
\text { (4 países) }\end{array}$ \\
\hline Repressão estatal & .020 & .011 & $.084^{* * *}$ & $.056^{*}$ \\
\hline Violência percebida & $-.068^{* * *}$ & $-.088^{* * *}$ & $.049^{* *}$ & .039 \\
\hline Dor e perda & $-{ }^{a}$ & .004 & $-{ }^{a}$ & -.001 \\
\hline $\operatorname{Sexo}(M=1, F=2)$ & $-.090^{* * *}$ & $-.112^{\star \star \star}$ & $.088^{* * *}$ & $.093^{* * *}$ \\
\hline Educação & $.139^{* * *}$ & $.082^{\star *}$ & $-.39^{*}$ & -.030 \\
\hline Padrão de vida ${ }^{b}$ & $.058^{* *}$ & $.142^{\star * *}$ & -.017 & $-.075^{\star *}$ \\
\hline Contato com mídia ${ }^{\mathrm{c}}$ & $.087^{* * *}$ & $.057^{* * *}$ & $.096^{* * *}$ & $.115^{\star * \star}$ \\
\hline Informação política ${ }^{d}$ & $.111^{* * *}$ & .032 & -.010 & -.030 \\
\hline $\mathrm{R}^{2}$ & .103 & .090 & .035 & .044 \\
\hline Erro padrão & .881 & .852 & .942 & .928 \\
\hline $\mathrm{F}$ & 66.187 & 32.239 & 20.750 & 14.950 \\
\hline Significância de F & .000 & .000 & .000 & .000 \\
\hline$(\mathrm{N})$ & $(4021)$ & $(2608)$ & $(4043)$ & $(2621)$ \\
\hline
\end{tabular}

Níveis de significância: * $\leq .05 ;{ }^{* *} \leq .01 ;{ }^{* *} \leq .001$

Item não disponível na amostra de 6 países.

Ver Tabela 4 para detalhes sobre a construção de índices. 
TABELA 7

Regressão múltipla, desobediência civil, apoio à supressão de liberdades, justificação de golpes, e alheamento das eleições, sobre repressão, violência percebida, dor e perda, contato com mídia, informação política e fatores demográficos (coeficientes beta), América Central urbana, todos os seis países.

\begin{tabular}{|c|c|c|c|c|c|}
\hline Variáveis dependentes & $\begin{array}{l}\text { DESOBEDIÊNCIA } \\
\text { CIVIL }\end{array}$ & $\begin{array}{l}\text { SUPRIMIR } \\
\text { LIBERDADES }\end{array}$ & $\begin{array}{l}\text { JUSTIFICA } \\
\text { GOLPES }\end{array}$ & $\begin{array}{l}\text { DERRUBAR } \\
\text { GOVERNO }\end{array}$ & $\begin{array}{l}\text { ALHEADO } \\
\text { ELEIÇÕES }\end{array}$ \\
\hline \multicolumn{6}{|l|}{ Variável independente } \\
\hline Repressão estatal & $-.129^{* * *}$ & $.184^{\star \star *}$ & $-.105^{\star \star *}$ & -.020 & $.079^{* * *}$ \\
\hline Violência percebida & -.007 & $-.125^{\star \star \star}$ & $.159^{* * *}$ & $.063^{* * *}$ & $.138^{* * *}$ \\
\hline $\operatorname{Sexo}(M=1, F=2)$ & -.012 & -.017 & .026 & -.011 & .019 \\
\hline Educação & -.101 & -.010 & -.007 & .003 & -.003 \\
\hline Padrão de vida ${ }^{\mathrm{b}}$ & $-.192^{* * *}$ & -.049 & .017 & $-.072^{* * *}$ & .009 \\
\hline Contato com mídia $^{\mathrm{c}}$ & $.042^{* *}$ & .028 & -.004 & -.001 & -.009 \\
\hline Informação política ${ }^{d}$ & $.159^{* * *}$ & $-.133^{\star * *}$ & $-.100^{\star * *}$ & $-.040^{*}$ & .011 \\
\hline $\mathrm{R}^{2}$ & .048 & .056 & .032 & .012 & .034 \\
\hline Erro padrão & 2.11 & 2.55 & .397 & 2.03 & .488 \\
\hline $\mathrm{F}$ & 28.93 & 33.45 & 18.08 & 28.90 & 21.15 \\
\hline Significância de F & .000 & .000 & .000 & .000 & .000 \\
\hline$(\mathrm{N})$ & (4012) & (3971) & (3801) & (4016) & (3955) \\
\hline
\end{tabular}

Níveis de significância: ${ }^{*} \leq .05 ;{ }^{* *} \leq .01 ;{ }^{* * *} \leq .001$. 


\section{BIBLIOGRAFIA}

ARMONY, Ariel. (1999) Unmasking Social Capital: Civic Participation, Interpersonal Trust, and the Role of the State in the United States and Argentina. Trabalho apresentado na Reunião Anual da Midwest Political Science Association, Chicago, abril 15-17.

BARSH, Russell Lawrence. (1993) Measuring Human Rights: Problems of Methodology and Purpose. Human Rights Quarterly 15:87-121.

BERKOWITZ, Peter. (1999) Virtue and the Making of Modern Liberalism. Princeton, Princeton University Press.

BOOTH, John A. (1991) Socioeconomic and Political Roots of National Revolts in Central America. Latin American Research Review 26 (No. 1): 33-73.

. (2000) Global Forces and Regime Change: Guatemala Within the Central American Context. Journal of Interamerican Studies and World Affairs (a sair).

BOOTH, John A. e RICHARD, Patricia Bayer. (1996) Repression, Participation, and Democratic Norms in Urban Central America. American Journal of Political Science, 40: 1205-1232.

(1998a) Civil Society, Political Capital, and Democratization in Central America. Journal of Politics, 60:780-800, (agosto).

(1998b) Civil Society and Political Context in Central America. American Behavioral Scientist 42: 33-46, (setembro).

. (1998c) Civil Society in Central America: The Dark Side? Trabalho apresentado na reunião da Midwest Political Science Association, Chicago, abril 23.

BOOTH, John A. e SELIGSON, Mitchell A. (1984) The Political Culture of Authoritarianism in Mexico: A Reexamination. Latin American Research Review 19, 1:106-124.

BOOTH, John A. e WALKER, Thomas W. (1999) Understanding Central America. Boulder, Westview Press.

COLLIER, David, ed. (1979) The New Authoritarianism in Latin America. Princeton, Princeton University Press.

Corradi, Juan E., FAGEN Patricia Weiss e GARRETÓN Manuel Antonio. (1992) Fear at the Edge: State Terror and Resistance in Latin America. Berkeley, University of California Press.

DAVENPORT, Christian. (1995) Multi-Dimensional Threat Perception and State Repression: An Inquiry into Why States Apply Negative Sanctions. American Journal of Political Science, 39: (No. 3):683-713.

, ed. (1999) Paths to State Repression: Human Rights and Contentious Politics in Comparative Perspective. Rowman and Littlefield.

DIAMOND, Larry. Developing Democracy: Toward Consolidation. Baltimore, Johns Hopkins.

DUFF, Ernest A. e MCCAMANT, John F. (1976) Violence and Repression in Latin America: $A$ Quantitative and Historical Analysis. Nova York, The Free Press.

EDWARDS, Bob, e FOLEY, Michael W. (2001) Beyond Tocqueville: Civil Society and the Social Capital Debate. In Bob Edwards, Michael W. Foley, e Mario Diani, eds. Beyond Tocqueville: Civil Society and the Social Capital Debate in Comparative Perspective. University Press of New England (a sair). 
FEIN, Helen. (1995) More Murder in the Middle: Life-Integrity Violations and Democracy in the World, 1987. Human Rights Quarterly 17,1:170-191.

FOLEY, Michael W. e EDWARDS, Bob. (1996) The Paradox of Civil Society. Journal of Democracy 7: 38-52.

(1998) Beyond Tocqueville: Civil Society and Social Capital in Comparative Perspective. American Behavioral Scientist 42 (No. 1): 5-20.

(2000) Is It Time to Disinvest in Social Capital? Journal of Public Policy .

GARTNER, Scott S. e REGAN, Patrick M. (1996) Threat and Repression: The Non-Linear Relationship between Government and Opposition Violence. Journal of Peace Research 33(3):273-288.

GASTIL, Raymond D. (1989) Freedom in the Comparative Survey: Definitions and Criteria. In Raymond Gastil, ed., Freedom in the World: Political Rights and Civil Liberties 1988-1989. Nova York, Freedom House.

GIBSON, James. 1988. "Political Intolerance and Repression During the McCarthy Red Scare." American Political Science Review 82(2):511-529.

GURR, Ted Robert. (1970) Why Men Rebel. Princeton, Princeton University Press.

GURR, Ted Robert e HARFF, Barbara. (1994) Ethnic Conflict in World Politics. Boulder, Westview Press.

JENNINGS, Kent. (1999) Political Responses to Pain and Loss. American Political Science Review 93(1):1-14.

KING, John C. (1998) Repression, Domestic Threat, and Interactions in Argentina and Chile. Journal of Political and Military Sociology 27 (Inverno): 1-37.

(1999) Ameliorating Effects of Democracy on Political Repression as Seen in 51 Countries Across 35 Years. In Christian Davenport, (ed.), Paths to State Repression: Human Rights and Contentious Politics in Comparative Perspective. Rowman and Littlefield .

LICHBACH, Mark Irving. (1995) The Rebel's Dilemma. Ann Arbor, University of Michigan Press.

LOVEMAN, Brian, DAVIES, Jr, Thomas M. e BEEZLEY, William H., eds. (1987). The Politics of Antipolitics: The Military in Latin America. Wilmington, Del., Scholarly Resources.

MASON, T. David e KRANE, Dale A. (1989) The Political Economy of Death Squads: Toward a Theory of the Impact of State-Sanctioned Terror. International Studies Quarterly 33:175-98, (junho).

MULLER, Edward N. et al. (1987) Education, Participation, and Support for Democratic Norms. Comparative Politics, 20:19-33, (Outubro).

PETRAS, James F.et al. (1986) Latin America: Bankers, Generals, and the Struggle for Social Justice. Totowa, N.J., Rowman and Littlefield.

PION-BERLIN, David. (1989) The Ideology of State Terror: Economic Doctrine and Political Repression in Argentina and Peru. Boulder, Lynne Rienner Publishers.

POE, Steven C. (1990) Human Rights and Foreign Aid: A Review of Quantitative Research and Prescriptions for Future Research. Human Rights Quarterly, 12:499-512.

(1991) Human Rights and the Allocation of U.S. Military Assistance. Journal of Peace Research, 28:205-216.

POE, Steven C. e TATE, C. Neal. (1994) Repression of Personal Integrity in the 1980s: A Global Analysis. American Political Science Review, 88(4):853-872. 
POWER, Timothy J. e CLARK, Mary A. (1999) Does Trust Matter? Interpersonal Trust and Democratic Values in Three Latin American Nations. Trabalho apresentado na Conference on Democracy and Development, Middelbury College, maio 8-9, 1999.

PUTNAM, Robert D. (1995) Bowling Alone: America's Declining Social Capital. Journal of Democracy, 6:65-78.

Schuster

2000) Bowling Alone: Civil Engagement in America. Nova York, Simon and

REGAN, Patrick M. (1999) Democracy, Threats, and Political Repression: Are Democracies Less Violent Internally? Trabalho apresentado na reunião da American Political Science Association, Atlanta, Georgia, (setembro).

RICHARD, Patricia Bayer e BOOTH, John A. (2000) Civil Society and Democratic Transition in Central America. In Thomas A. Walker e Ariel C. Armony. Repression, Resistance, and Democratic Transition in Central America. Wilmington, Del.: Scholarly Resources .

ROSENBLUM, Nancy L. (1998) Membership and Morals: The Personal Uses of Pluralism. Princeton, Princeton University Press.

SCHUDSON, Michael. (1998) The Good Citizen: A History of American Civic Life. Nova York, The Free Press.

SELIGSON, Mitchell A. e BOOTH, John A. (1993) Political Culture and Regime Type: Evidence from Nicaragua and Costa Rica. Journal of Politics, 55:777-792, (Agosto).

SELIGSON, Mitchell A. e GÓMEZ B., Miguel. (1989) Ordinary Elections in Extraordinary Times. In John A. Booth and Mitchell A. Seligson, eds. Elections and Democracy in Central America. Chapel Hill, University of North Carolina Press.

STOHL, Michael e LOPEZ, George A. eds. (1984) The State as Terrorist. Westport, Conn., Greenwood Press.

, eds. (1986) Government Violence and Repression: An Agenda for Research. Westport, Conn., Greenwood Press.

eds. (1988) Terrible Beyond Endurance: The Foreign Policy of State Terrorism. Nova York, Greenwood Press.

TILLY, Charles. (1978) From Mobilization to Revolution. Reading, Mass., Addison Wesley.

Tradução do original em inglês de Pedro Maia Soares 